\title{
Monotone variational inequalities, generalized equilibrium problems and fixed point methods
}

Shenghua Wang*

\section{"Correspondence:}

hdwangsh@yeah.net

School of Mathematics and Physics,

North China Electric Power

University, Baoding, 071003, China

\begin{abstract}
In this paper, we study monotone variational inequalities and generalized equilibrium problems. Weak convergence theorems are established based on a fixed point method in the framework of Hilbert spaces.
\end{abstract}

Keywords: fixed point; generalized equilibrium problem; monotone operator; nonexpansive mapping

\section{Introduction and preliminaries}

It is well known that many nonlinear problems can be reduced to the search for solutions of monotone variational inequalities. Fixed point methods are often used for finding and approximating such solutions. In this paper, we always assume that $H$ is a real Hilbert space with the inner product $\langle\cdot, \cdot\rangle$ and the norm $\|\cdot\|$. Let $C$ be a nonempty closed and convex subset of $H$. Let $S: C \rightarrow C$ be a mapping. In this paper, we use $F(S)$ to stand for the set of fixed points. Recall that $S$ is said to be nonexpansive iff $\|S x-S y\| \leq\|x-y\|, \forall x, y \in C$. $S$ is said to be $\kappa$-strictly pseudocontractive iff there exists a constant $\kappa \in[0,1)$ such that

$$
\|S x-S y\|^{2} \leq\|x-y\|^{2}+\kappa\|x-y-S x+S y\|^{2}, \quad \forall x, y \in C .
$$

The class of strict pseudocontractions was introduced by Browder and Petryshyn [1]. It is clear that the class of $\kappa$-strict pseudocontractions includes the class of nonexpansive mappings as a special case.

Let $A: C \rightarrow H$ be a mapping. Recall that $A$ is said to be monotone iff $\langle A x-A y, x-y\rangle \geq 0$, $\forall x, y \in C$. $A$ is said to be $\alpha$-inverse strongly monotone iff there exists a constant $\alpha>0$ such that

$$
\langle A x-A y, x-y\rangle \geq \alpha\|A x-A y\|^{2}, \quad \forall x, y \in C .
$$

It is clear that $\alpha$-inverse strongly monotone is monotone and Lipschitz continuous.

Recall that the classical variational inequality, denoted by $\operatorname{VI}(C, A)$, is to find $x \in C$ such that

$$
\langle A x, y-x\rangle \geq 0, \quad \forall y \in C .
$$

O2014 Wang; licensee Springer. This is an Open Access article distributed under the terms of the Creative Commons Attribution License (http://creativecommons.org/licenses/by/2.0), which permits unrestricted use, distribution, and reproduction in any medium, provided the original work is properly cited. 
One can see that variational inequality (1.1) is equivalent to a fixed point problem. The element $x \in C$ is a solution of variational inequality (1.1) iff $x \in C$ satisfies the fixed point equation $x=\operatorname{Proj}_{C}(x-\lambda A x)$, where $\lambda>0$ is a constant. This alternative equivalent formulation plays a significant role in the studies of variational inequalities and related optimization problems. If $A$ is $\alpha$-inverse-strongly monotone and $\lambda \in(0,2 \alpha]$, then the mapping $\operatorname{Proj}_{C}(I-\lambda A)$ is nonexpansive; see [2] and the references therein.

A set-valued mapping $T: H \rightarrow 2^{H}$ is said to be monotone if, for all $x, y \in H, f \in T x$ and $g \in T y$ imply $\langle x-y, f-g\rangle>0$. A monotone mapping $T: H \rightarrow 2^{H}$ is maximal if the graph $G(T)$ of $T$ is not properly contained in the graph of any other monotone mapping. It is known that a monotone mapping $T$ is maximal if and only if, for any $(x, f) \in H \times H$, $\langle x-y, f-g\rangle \geq 0$ for all $(y, g) \in G(T)$ implies $f \in T x$. The class of monotone operators is one of the most important classes of operators. Within the past several decades, many authors have been devoted to the studies on the existence and convergence of different schemes for zero points for maximal monotone operators; see [3-15] and the references therein.

Let $\mathbb{R}$ denote the set of real numbers, and let $F$ be a bifunction of $C \times C$ into $\mathbb{R}$. Recall that the following generalized equilibrium problem is to find an $x$ such that

$$
F(x, y)+\langle A x, y-x\rangle \geq 0, \quad \forall y \in C .
$$

In this paper, the solution set of the equilibrium problem is denoted by $\operatorname{GEP}(F, A)$, i.e.,

$$
\operatorname{GEP}(F, A)=\{x \in C: F(x, y)+\langle A x, y-x\rangle \geq 0, \forall y \in C\} .
$$

To study equilibrium problem (1.2), we may assume that $F$ satisfies the following conditions:

(A1) $F(x, x)=0$ for all $x \in C$;

(A2) $F$ is monotone, i.e., $F(x, y)+F(y, x) \leq 0$ for all $x, y \in C$;

(A3) for each $x, y, z \in C$,

$$
\lim _{t \downarrow 0} F(t z+(1-t) x, y) \leq F(x, y)
$$

(A4) for each $x \in C, y \mapsto F(x, y)$ is convex and lower semi-continuous.

If $F \equiv 0$, the generalized equilibrium problem is reduced to variational inequality (1.1). If $A \equiv 0$, the generalized equilibrium problem is reduced to the following equilibrium problem: find an $x$ such that

$$
F(x, y) \geq 0, \quad \forall y \in C
$$

In this paper, the solution set of the equilibrium problem is denoted by $E P(F)$, i.e.,

$$
E P(F)=\{x \in C: F(x, y) \geq 0, \forall y \in C\} .
$$

Equilibrium problems, which were introduced by Blum and Oettli [16], have intensively been studied. It has been shown that equilibrium problems cover fixed point problems, 
variational inequality problems, inclusion problems, saddle point problems, complementarity problem, minimization problem, and Nash equilibrium problem. Equilibrium problem has emerged as an effective and powerful tool for studying a wide class of problems which arise in economics, finance, image reconstruction, ecology, transportation, network, elasticity, and optimization. Recently, many authors studied the numerical solution of equilibriums (1.2) and (1.3) based on iterative methods. Convergence theorems are established in a different framework of spaces; see [17-24] and the references therein.

In this paper, an iterative algorithm is investigated for monotone variational inequalities and generalized equilibrium problems. Weak convergence of the algorithm is obtained in the framework of Hilbert spaces.

Recall that a space is said to satisfy Opial's condition [25] if, for any sequence $\left\{x_{n}\right\} \subset H$ with $x_{n} \rightarrow x$, where $\rightarrow$ denotes the weak convergence, the inequality

$$
\liminf _{n \rightarrow \infty}\left\|x_{n}-x\right\|<\liminf _{n \rightarrow \infty}\left\|x_{n}-y\right\|
$$

holds for every $y \in H$ with $y \neq x$. Indeed, the above inequality is equivalent to the following:

$$
\limsup _{n \rightarrow \infty}\left\|x_{n}-x\right\|<\limsup _{n \rightarrow \infty}\left\|x_{n}-y\right\| .
$$

Recall that a function is lower semi-continuous at some point $x_{0}$ if $\liminf _{x \rightarrow x_{0}} f(x) \geq f\left(x_{0}\right)$. It is known that the norm is lower semi-continuous. In order to prove our main results, we also need the following lemmas.

Lemma 1.1 [16,17] Let $C$ be a nonempty closed convex subset of $H$, and let $F: C \times C \rightarrow \mathbb{R}$ be a bifunction satisfying (A1)-(A4). Then, for any $r>0$ and $x \in H$, there exists $z \in C$ such that

$$
F(z, y)+\frac{1}{r}\langle y-z, z-x\rangle \geq 0, \quad \forall y \in C .
$$

Further, define

$$
T_{r} x=\left\{z \in C: F(z, y)+\frac{1}{r}\langle y-z, z-x\rangle \geq 0, \forall y \in C\right\}
$$

for all $r>0$ and $x \in H$. Then the following hold:

(a) $T_{r}$ is single-valued;

(b) $T_{r}$ is firmly nonexpansive, i.e., for any $x, y \in H$,

$$
\left\|T_{r} x-T_{r} y\right\|^{2} \leq\left\langle T_{r} x-T_{r} y, x-y\right\rangle ;
$$

(c) $F\left(T_{r}\right)=E P(F)$;

(d) $E P(F)$ is closed and convex.

Lemma 1.2 [4] Let $A$ be a monotone mapping of $C$ into $H$ and $N_{C} v$ be the normal cone to $C$ at $v \in C$, i.e.,

$$
N_{C} v=\{w \in H:\langle v-u, w\rangle \geq 0, \forall u \in C\}
$$




$$
T v= \begin{cases}A v+N_{C} v, & v \in C, \\ \emptyset, & v \notin C .\end{cases}
$$

Then $T$ is maximal monotone and $0 \in T v$ if and only if $\langle A v, u-v\rangle \geq 0$ for all $u \in C$.

Lemma 1.3 [26] Let $\left\{a_{n}\right\},\left\{b_{n}\right\}$, and $\left\{c_{n}\right\}$ be three nonnegative sequences satisfying the following condition:

$$
a_{n+1} \leq\left(1+b_{n}\right) a_{n}+c_{n}, \quad \forall n \geq n_{0}
$$

where $n_{0}$ is some nonnegative integer, $\sum_{n=1}^{\infty} b_{n}<\infty$ and $\sum_{n=1}^{\infty} c_{n}<\infty$. Then the limit $\lim _{n \rightarrow \infty} a_{n}$ exists.

Lemma 1.4 [27] Let $\left\{a_{n}\right\}_{n=1}^{\infty}$ be real numbers in $[0,1]$ such that $\sum_{n=1}^{\infty} a_{n}=1$. Then we have the following:

$$
\left\|\sum_{i=1}^{\infty} a_{i} x_{i}\right\|^{2} \leq \sum_{i=1}^{\infty} a_{i}\left\|x_{i}\right\|^{2}
$$

for any given bounded sequence $\left\{x_{n}\right\}_{n=1}^{\infty}$ in $H$.

\section{Main results}

Theorem 2.1 Let $C$ be a nonempty closed and convex subset of $H$, and let $A: C \rightarrow H$ be an L-Lipschitz continuous and monotone mapping. Let $F_{m}$ be a bifunction from $C \times$ $C$ to $\mathbb{R}$ which satisfies (A1)-(A4), and let $B_{m}: C \rightarrow C$ be a $\kappa_{m}$-inverse strongly monotone mapping for each $m \geq 1$. Assume that $\mathcal{F}:=\bigcap_{m=1}^{\infty} \operatorname{GEP}\left(F_{m}, B_{m}\right) \cap V I(C, A)$ is not empty. Let $\left\{\alpha_{n}\right\},\left\{\delta_{n, m}\right\}$ be real number sequences in $[0,1]$. Let $\left\{\lambda_{n}\right\}$ and $\left\{r_{n, m}\right\}$ be positive real number sequences. Let $\left\{x_{n}\right\}$ be a sequence generated in the following manner:

$$
\left\{\begin{array}{l}
x_{1} \in C \\
z_{n, m} \in C \text { such that } F_{m}\left(z_{n, m}, z\right)+\left\langle B_{m} x_{n}, z-z_{n, m}\right\rangle+\frac{1}{r_{n, m}}\left\langle z-z_{n, m}, z_{n, m}-x_{n}\right\rangle \geq 0, \\
y_{n}=\operatorname{Proj}_{C}\left(\sum_{m=1}^{\infty} \delta_{n, m} z_{n, m}-\lambda_{n} A \sum_{m=1}^{\infty} \delta_{n, m} z_{n, m}\right), \\
x_{n+1}=\alpha_{n} x_{n}+\left(1-\alpha_{n}\right) \operatorname{Proj}_{C}\left(\sum_{m=1}^{\infty} \delta_{n, m} z_{n, m}-\lambda_{n} A y_{n}\right), \quad n \geq 1 .
\end{array}\right.
$$

Assume that $\left\{\alpha_{n}\right\},\left\{\delta_{n, m}\right\},\left\{\lambda_{n}\right\}$, and $\left\{r_{n, m}\right\}$ satisfy the following restrictions:

(a) $0 \leq \alpha_{n} \leq a^{\prime}<1$;

(b) $\sum_{m=1}^{\infty} \delta_{n, m}=1$, and $0<\delta \leq \delta_{n, m} \leq 1$;

(c) $\liminf _{n \rightarrow \infty} r_{n, m}>0$, and $\lambda \leq \lambda_{n} \leq \lambda^{\prime}$, where $\lambda, \lambda^{\prime} \in(0,1 / L)$.

Then the sequence $\left\{x_{n}\right\}$ weakly converges to some point $\bar{x} \in \mathcal{F}$.

Proof We first show that the sequence $\left\{x_{n}\right\}$ is bounded. Set $u_{n}=\operatorname{Proj}_{C}\left(v_{n}-\lambda_{n} A y_{n}\right)$, where $v_{n}=\sum_{m=1}^{\infty} \delta_{n, m} z_{n, m}$. Letting $p \in \mathcal{F}$, we see that

$$
\begin{aligned}
\left\|u_{n}-p\right\|^{2} & \leq\left\|v_{n}-p\right\|^{2}-\left\|v_{n}-u_{n}\right\|^{2}+2 \lambda_{n}\left\langle A y_{n}, p-u_{n}\right\rangle \\
& =\left\|v_{n}-p\right\|^{2}-\left\|v_{n}-u_{n}\right\|^{2}+2 \lambda_{n}\left(\left\langle A y_{n}-A p, p-y_{n}\right\rangle+\left\langle A p, p-y_{n}\right\rangle\right.
\end{aligned}
$$




$$
\begin{aligned}
& \left.+\left\langle A y_{n}, y_{n}-u_{n}\right\rangle\right) \\
\leq & \left\|v_{n}-p\right\|^{2}-\left\|v_{n}-y_{n}\right\|^{2}-\left\|y_{n}-u_{n}\right\|^{2}+2\left\langle v_{n}-\lambda_{n} A y_{n}-y_{n}, u_{n}-y_{n}\right\rangle
\end{aligned}
$$

Since $A$ is $L$-Lipschitz continuous and $y_{n}=\operatorname{Proj}_{C}\left(v_{n}-\lambda_{n} A v_{n}\right)$, we find that

$$
\begin{aligned}
& \left\langle v_{n}-\lambda_{n} A y_{n}-y_{n}, u_{n}-y_{n}\right\rangle \\
& \quad=\left\langle v_{n}-\lambda_{n} A v_{n}-y_{n}, u_{n}-y_{n}\right\rangle+\left\langle\lambda_{n} A v_{n}-\lambda_{n} A y_{n}, u_{n}-y_{n}\right\rangle \\
& \quad \leq \lambda_{n} L\left\|v_{n}-y_{n}\right\|\left\|u_{n}-y_{n}\right\| .
\end{aligned}
$$

It follows that

$$
\begin{aligned}
\left\|u_{n}-p\right\|^{2} & \leq\left\|v_{n}-p\right\|^{2}-\left\|v_{n}-y_{n}\right\|^{2}-\left\|y_{n}-u_{n}\right\|^{2}+2 \lambda_{n} L\left\|v_{n}-y_{n}\right\|\left\|u_{n}-y_{n}\right\| \\
& \leq\left\|v_{n}-p\right\|^{2}+\left(\lambda_{n}^{2} L^{2}-1\right)\left\|v_{n}-y_{n}\right\|^{2} .
\end{aligned}
$$

On the other hand, we obtain from the restriction (c) that

$$
\begin{aligned}
\left\|v_{n}-p\right\|^{2} & \leq \sum_{m=1}^{\infty} \delta_{n, m}\left\|z_{n, m}-p\right\|^{2} \\
& \leq \sum_{m=1}^{\infty} \delta_{n, m}\left\|T_{r_{n, m}}\left(I-r_{n, m} B_{m}\right) x_{n}-p\right\|^{2} \\
& \leq\left\|x_{n}-p\right\|^{2} .
\end{aligned}
$$

Substituting (2.2) into (2.1), we obtain that $\left\|u_{n}-p\right\|^{2} \leq\left\|x_{n}-p\right\|^{2}+\left(\lambda_{n}^{2} L^{2}-1\right)\left\|v_{n}-y_{n}\right\|^{2}$. This in turn implies from the restriction (c) that

$$
\begin{aligned}
\left\|x_{n+1}-p\right\|^{2} & \leq \alpha_{n}\left\|x_{n}-p\right\|^{2}+\left(1-\alpha_{n}\right)\left\|u_{n}-p\right\|^{2} \\
& \leq \alpha_{n}\left\|x_{n}-p\right\|^{2}+\left(1-\alpha_{n}\right)\left(\left\|x_{n}-p\right\|^{2}+\left(\lambda_{n}^{2} L^{2}-1\right)\left\|v_{n}-y_{n}\right\|^{2}\right) \\
& \leq\left\|x_{n}-p\right\|^{2}+\left(1-\alpha_{n}\right)\left(\lambda_{n}^{2} L^{2}-1\right)\left\|v_{n}-y_{n}\right\|^{2} \\
& \leq\left\|x_{n}-p\right\|^{2} .
\end{aligned}
$$

It follows from Lemma 1.3 that $\lim _{n \rightarrow \infty}\left\|x_{n}-p\right\|$ exists. This in turn shows that $\left\{x_{n}\right\}$ is bounded. From (2.3), we also have that

$$
\left(1-\alpha_{n}\right)\left(1-\lambda_{n}^{2} L^{2}\right)\left\|v_{n}-y_{n}\right\|^{2} \leq\left\|x_{n}-p\right\|^{2}-\left\|x_{n+1}-p\right\|^{2} .
$$

This implies from the restrictions (a) and (c) that

$$
\lim _{n \rightarrow \infty}\left\|v_{n}-y_{n}\right\|=0
$$

Since $\left\|y_{n}-u_{n}\right\| \leq \lambda L\left\|v_{n}-y_{n}\right\|$, we find from (2.4) $\lim _{n \rightarrow \infty}\left\|y_{n}-u_{n}\right\|=0$. Hence, we have

$$
\lim _{n \rightarrow \infty}\left\|v_{n}-u_{n}\right\|=0
$$


Notice that

$$
\begin{aligned}
\left\|z_{n, m}-p\right\|^{2}= & \left\|T_{r_{n, m}}\left(I-r_{n, m} B_{m}\right) x_{n}-T_{r_{n, m}}\left(I-r_{n, m} B_{m}\right) p\right\|^{2} \\
\leq & \left\langle\left(I-r_{n, m} B_{m}\right) x_{n}-\left(I-r_{n, m} B_{m}\right) p, z_{n, m}-p\right\rangle \\
= & \frac{1}{2}\left(\left\|\left(I-r_{n, m} B_{m}\right) x_{n}-\left(I-r_{n, m} B_{m}\right) p\right\|^{2}+\left\|z_{n, m}-p\right\|^{2}\right. \\
& \left.-\left\|\left(I-r_{n, m} B_{m}\right) x_{n}-\left(I-r_{n, m} B_{m}\right) p-\left(z_{n, m}-p\right)\right\|^{2}\right) \\
\leq & \frac{1}{2}\left(\left\|x_{n}-p\right\|^{2}+\left\|z_{n, m}-p\right\|^{2}-\left\|\left(x_{n}-z_{n, m}\right)-r_{n, m}\left(B_{m} x_{n}-B_{m} p\right)\right\|^{2}\right) \\
= & \frac{1}{2}\left(\left\|x_{n}-p\right\|^{2}+\left\|z_{n, m}-p\right\|^{2}-\left\|x_{n}-z_{n, m}\right\|^{2}\right. \\
& \left.+2 r_{n, m}\left\langle x_{n}-z_{n, m}, B_{m} x_{n}-B_{m} p\right\rangle-r_{n, m}^{2}\left\|B_{m} x_{n}-B_{m} p\right\|^{2}\right) .
\end{aligned}
$$

This implies that

$$
\left\|z_{n, m}-p\right\|^{2} \leq\left\|x_{n}-p\right\|^{2}-\left\|x_{n}-z_{n, m}\right\|^{2}+2 r_{n, m}\left\|x_{n}-z_{n, m}\right\|\left\|B_{m} x_{n}-B_{m} p\right\| .
$$

It follows from Lemma 1.4 that

$$
\begin{aligned}
\left\|v_{n}-p\right\|^{2} & \leq \sum_{m=1}^{\infty} \delta_{n, m}\left\|z_{n, m}-p\right\|^{2} \\
& \leq \sum_{m=1}^{\infty} \delta_{n, m}\left(\left\|x_{n}-p\right\|^{2}-\left\|z_{n, m}-x_{n}\right\|^{2}+2 r_{n, m}\left\|x_{n}-z_{n, m}\right\|\left\|B_{m} x_{n}-B_{m} p\right\|\right) \\
& =\left\|x_{n}-p\right\|^{2}-\sum_{m=1}^{\infty} \delta_{n, m}\left\|z_{n, m}-x_{n}\right\|^{2}+2 \sum_{m=1}^{\infty} r_{n, m}\left\|x_{n}-z_{n, m}\right\|\left\|B_{m} x_{n}-B_{m} p\right\| .
\end{aligned}
$$

By use of (2.3), we find that

$$
\begin{aligned}
\left\|x_{n+1}-p\right\|^{2} \leq & \alpha_{n}\left\|x_{n}-p\right\|^{2}+\left(1-\alpha_{n}\right)\left\|u_{n}-p\right\|^{2} \\
\leq & \alpha_{n}\left\|x_{n}-p\right\|^{2}+\left(1-\alpha_{n}\right)\left\|v_{n}-p\right\|^{2} \\
\leq & \left\|x_{n}-p\right\|^{2}-\left(1-\alpha_{n}\right) \sum_{m=1}^{\infty} \delta_{n, m}\left\|z_{n, m}-x_{n}\right\|^{2} \\
& +2\left(1-\alpha_{n}\right) \sum_{m=1}^{\infty} r_{n, m}\left\|x_{n}-z_{n, m}\right\|\left\|B_{m} x_{n}-B_{m} p\right\| .
\end{aligned}
$$

This implies that

$$
\begin{aligned}
\left(1-\alpha_{n}\right) \sum_{m=1}^{\infty} \delta_{n, m}\left\|z_{n, m}-x_{n}\right\|^{2} \leq & \left\|x_{n}-p\right\|^{2}-\left\|x_{n+1}-p\right\|^{2} \\
& +2\left(1-\alpha_{n}\right) \sum_{m=1}^{\infty} r_{n, m}\left\|x_{n}-z_{n, m}\right\|\left\|B_{m} x_{n}-B_{m} p\right\| .
\end{aligned}
$$


Since $T_{r_{n, m}}$ is firmly nonexpansive, we find from the convexity of $\|\cdot\|^{2}$ that $\lim _{n \rightarrow \infty} \| B_{m} x_{n}-$ $B_{m} p \|=0$. It follows that

$$
\lim _{n \rightarrow \infty}\left\|z_{n, m}-x_{n}\right\|=0
$$

Since $\left\{x_{n}\right\}$ is bounded, we may assume that a subsequence $\left\{x_{n_{i}}\right\}$ of $\left\{x_{n}\right\}$ converges weakly to $\xi$. It follows that $\left\{z_{n_{i}, m}\right\}$ converges weakly to $\xi$ for each $m \geq 1$. Next, we show that $\xi \in$ $\operatorname{GEP}\left(F_{m}, B_{m}\right)$. Since $z_{n, m}=T_{r_{n, m}}\left(I-r_{n, m} B_{m}\right) x_{n}$, we have

$$
F_{m}\left(z_{n, m}, z\right)+\left\langle B_{m} x_{n}, z-z_{n, m}\right\rangle+\frac{1}{r_{n, m}}\left\langle z-z_{n, m}, z_{n, m}-x_{n}\right\rangle \geq 0, \quad \forall z \in C .
$$

From assumption (A2), we see that

$$
\left\langle B_{m} x_{n}, z-z_{n, m}\right\rangle+\frac{1}{r_{n, m}}\left\langle z-z_{n, m}, z_{n, m}-x_{n}\right\rangle \geq F_{m}\left(z, z_{n, m}\right), \quad \forall z \in C .
$$

Replacing $n$ by $n_{i}$, we arrive at

$$
\left\langle B_{m} x_{n_{j}}, z-z_{n_{j}, m}\right\rangle+\left\langle z-z_{n_{i}, m}, \frac{z_{n_{i}, m}-x_{n_{i}}}{r_{n_{i}, m}}\right\rangle \geq F_{m}\left(z, z_{n_{i}, m}\right), \quad \forall z \in C
$$

For $t_{m}$ with $0<t_{m} \leq 1$ and $\rho_{m} \in C$, let $\rho_{m}=t_{m} \rho+\left(1-t_{m}\right) \xi$. Since $\rho \in C$ and $\xi \in C$, we have $\rho_{m} \in C$. It follows that

$$
\begin{aligned}
\left\langle\rho_{m}-z_{n_{i}, m}, B_{m} \rho_{m}\right\rangle \geq & \left\langle\rho_{m}-z_{n_{i}, m}, B_{m} \rho_{m}\right\rangle-\left\langle B_{m} x_{n_{i}}, \rho_{m}-z_{n_{i}, m}\right\rangle \\
& -\left\langle\rho_{m}-z_{n_{i}, m}, \frac{z_{n_{i}, m}-x_{n_{i}}}{r_{n_{i}, m}}\right\rangle+F_{m}\left(\rho_{m}, z_{n_{i}, m}\right) \\
= & \left\langle\rho_{m}-z_{n_{i}, m}, B_{m} \rho_{m}-B_{m} z_{n_{i}, m}\right\rangle+\left\langle\rho_{m}-z_{n_{i}, m}, B_{m} z_{n_{i}, m}-B_{m} x_{n_{i}}\right\rangle \\
& -\left\langle\rho_{m}-z_{n_{i}, m}, \frac{z_{n_{i}, m}-x_{n_{i}}}{r_{n_{i}, m}}\right\rangle+F_{m}\left(\rho_{m}, z_{n_{i}, m}\right) .
\end{aligned}
$$

It follows from (A4) and (2.6) that

$$
\left\langle\rho_{m}-\xi, B_{m} \rho_{m}\right\rangle \geq F_{m}\left(\rho_{m}, \xi\right) \quad \text { as } i \rightarrow \infty .
$$

From (A1) and (A4), we see

$$
\begin{aligned}
0 & =F_{m}\left(\rho_{m}, \rho_{m}\right) \leq t_{m} F_{m}\left(\rho_{m}, \rho\right)+\left(1-t_{m}\right) F_{m}\left(\rho_{m}, \xi\right) \\
& \leq t_{m} F_{m}\left(\rho_{m}, \rho\right)+\left(1-t_{m}\right)\left\langle\rho_{m}-\xi, B_{m} \rho_{m}\right\rangle \\
& =t_{m} F_{m}\left(\rho_{m}, \rho\right)+\left(1-t_{m}\right) t_{m}\left\langle\rho-\xi, B_{m} \rho_{m}\right\rangle,
\end{aligned}
$$

which yields that

$$
F_{m}\left(\rho_{m}, \rho\right)+\left(1-t_{m}\right)\left\langle\rho-\xi, B_{m} \rho_{m}\right\rangle \geq 0 .
$$


Letting $t \rightarrow 0$ in the above inequality, we arrive at

$$
F_{m}(\xi, \rho)+\left\langle\rho-\xi, B_{m} \xi\right\rangle \geq 0
$$

This completes the proof that $\xi \in \bigcap_{m=1}^{\infty} G E P\left(F_{m}, B_{m}\right)$. Next, we show that $\xi \in V I(C, A)$. In fact, let $T$ be the maximal monotone mapping defined by

$$
T x= \begin{cases}A x+N_{C} x, & x \in C, \\ \emptyset, & x \notin C .\end{cases}
$$

For any given $(x, y) \in G(T)$, we have $y-A x \in N_{C} x$. So, we have $\langle x-m, y-A x\rangle \geq 0$ for all $m \in C$. On the other hand, we have $u_{n}=\operatorname{Proj}_{C}\left(v_{n}-\lambda_{n} A y_{n}\right)$. We obtain that $\left\langle v_{n}-\lambda_{n} A y_{n}-\right.$ $\left.u_{n}, u_{n}-x\right\rangle \geq 0$ and hence $\left\langle x-u_{n}, \frac{u_{n}-v_{n}}{\lambda_{n}}+A y_{n}\right\rangle \geq 0$. In view of the monotonicity of $A$, we see that

$$
\begin{aligned}
\left\langle x-u_{n_{i}}, y\right\rangle & \geq\left\langle x-u_{n_{i}}, A x\right\rangle \\
\geq & \left\langle x-u_{n_{i}}, A x\right\rangle-\left\langle x-u_{n_{i}}, \frac{u_{n_{i}}-v_{n_{i}}}{\lambda_{n_{i}}}+A y_{n_{i}}\right\rangle \\
& =\left\langle x-u_{n_{i}}, A x-A u_{n_{i}}\right\rangle+\left\langle x-u_{n_{i}}, A u_{n_{i}}-A y_{n_{i}}\right\rangle-\left\langle x-u_{n_{i}}, \frac{u_{n_{i}}-v_{n_{i}}}{\lambda_{n_{i}}}\right\rangle \\
& \geq\left\langle x-u_{n_{i}}, A u_{n_{i}}-A y_{n_{i}}\right\rangle-\left\langle x-u_{n_{i}}, \frac{u_{n_{i}}-v_{n_{i}}}{\lambda_{n_{i}}}\right\rangle .
\end{aligned}
$$

On the other hand, we see that $\left\|v_{n}-x_{n}\right\| \leq \sum_{m=1}^{\infty} \delta_{n, m}\left\|z_{n, m}-x_{n}\right\|$. It follows that

$$
\lim _{n \rightarrow \infty}\left\|v_{n}-x_{n}\right\|=0
$$

Notice that

$$
\left\|u_{n}-x_{n}\right\| \leq\left\|u_{n}-v_{n}\right\|+\left\|v_{n}-x_{n}\right\| .
$$

Combining (2.5) with (2.8), one finds

$$
\lim _{n \rightarrow \infty}\left\|u_{n}-x_{n}\right\|=0 .
$$

This in turn implies that $u_{n_{i}} \rightarrow \xi$. It follows that $\langle x-\xi, y\rangle \geq 0$. Notice that $T$ is maximal monotone and hence $0 \in T \xi$. This shows from Lemma 1.2 that $\xi \in V I(C, A)$. This completes the proof that $\xi \in \mathcal{F}$.

Finally, we show that the whole sequence $\left\{x_{n}\right\}$ weakly converges to $\xi$. Let $\left\{x_{n_{j}}\right\}$ be another subsequence of $\left\{x_{n}\right\}$ converging weakly to $\xi^{\prime}$, where $\xi^{\prime} \neq \xi$. In the same way, we can show that $\xi^{\prime} \in \mathcal{F}$. Since the space $H$ enjoys Opial's condition [25], we, therefore, obtain that

$$
\begin{aligned}
d & =\liminf _{i \rightarrow \infty}\left\|x_{n_{i}}-\xi\right\|<\liminf _{i \rightarrow \infty}\left\|x_{n_{i}}-\xi^{\prime}\right\| \\
& =\liminf _{j \rightarrow \infty}\left\|x_{j}-\xi^{\prime}\right\|<\liminf _{j \rightarrow \infty}\left\|x_{j}-\xi\right\|=d .
\end{aligned}
$$

This is a contradiction. Hence $\xi=\xi^{\prime}$. This completes the proof. 
If $B_{m} \equiv 0$, we have the following result on equilibrium problem (1.3).

Corollary 2.2 Let $C$ be a nonempty closed and convex subset of $H$, and let $A: C \rightarrow H$ be an L-Lipschitz continuous and monotone mapping. Let $F_{m}$ be a bifunction from $C \times C$ to $\mathbb{R}$ which satisfies (A1)-(A4) for each $m \geq 1$. Assume that $\mathcal{F}:=\bigcap_{m=1}^{\infty} E P\left(F_{m}\right) \cap V I(C, A)$ is not empty. Let $\left\{\alpha_{n}\right\},\left\{\delta_{n, m}\right\}$ be real number sequences in $[0,1]$. Let $\left\{\lambda_{n}\right\}$ and $\left\{r_{n, m}\right\}$ be positive real number sequences. Let $\left\{x_{n}\right\}$ be a sequence generated in the following manner:

$$
\left\{\begin{array}{l}
x_{1} \in C, \\
z_{n, m} \in C \text { such that } F_{m}\left(z_{n, m}, z\right)+\frac{1}{r_{n, m}}\left\langle z-z_{n, m}, z_{n, m}-x_{n}\right\rangle \geq 0, \\
y_{n}=\operatorname{Proj}_{C}\left(\sum_{m=1}^{\infty} \delta_{n, m} z_{n, m}-\lambda_{n} A \sum_{m=1}^{\infty} \delta_{n, m} z_{n, m}\right), \\
x_{n+1}=\alpha_{n} x_{n}+\left(1-\alpha_{n}\right) \operatorname{Proj}_{C}\left(\sum_{m=1}^{\infty} \delta_{n, m} z_{n, m}-\lambda_{n} A y_{n}\right), \quad n \geq 1 .
\end{array}\right.
$$

Assume that $\left\{\alpha_{n}\right\},\left\{\delta_{n, m}\right\},\left\{\lambda_{n}\right\}$, and $\left\{r_{n, m}\right\}$ satisfy the following restrictions:

(a) $0<a \leq \alpha_{n} \leq b<1$;

(b) $\sum_{m=1}^{\infty} \delta_{n, m}=1$, and $0<c \leq \delta_{n, m} \leq 1$;

(c) $\liminf _{n \rightarrow \infty} r_{n, m}>0$, and $d \leq \lambda_{n} \leq e$, where $d, e \in(0,1 / L)$.

Then the sequence $\left\{x_{n}\right\}$ weakly converges to some point $\bar{x} \in \mathcal{F}$.

Corollary 2.3 Let $C$ be a nonempty closed and convex subset of $H$, and let $A: H \rightarrow H$ be an L-Lipschitz continuous and monotone mapping. Assume that $A^{-1}(0)$ is not empty. Let $\left\{\alpha_{n}\right\}$ be a real number sequence in $[0,1]$, and let $\left\{\lambda_{n}\right\}$ be a positive real number sequence. Let $\left\{x_{n}\right\}$ be a sequence generated in the following manner:

$$
x_{1} \in C, \quad x_{n+1}=\alpha_{n} x_{n}+\left(1-\alpha_{n}\right)\left(x_{n}-\lambda_{n} A\left(x_{n}-\lambda_{n} A x_{n}\right)\right), \quad n \geq 1 .
$$

Assume that $\left\{\alpha_{n}\right\}$ and $\left\{\lambda_{n}\right\}$ satisfy the following restrictions:

(a) $0<a \leq \alpha_{n} \leq b<1$;

(b) $c \leq \lambda_{n} \leq d$, where $c, d \in(0,1 / L)$.

Then the sequence $\left\{x_{n}\right\}$ weakly converges to some point $\bar{x} \in A^{-1}(0)$.

Proof Put $F_{m}(x, y) \equiv 0$ for all $x, y \in C$, and $r_{n, m} \equiv 1$. Notice that $A^{-1}(0)=V I(H, A)$, and $P_{H}=I$, we easily find from Corollary 2.2 the desired conclusion.

Letting $F_{m}=0, B_{m}=0$, and $r_{n, m}=1$ in $\Gamma$, we have the extragradient-type algorithm (see Table 1).

Corollary 2.4 Let $C$ be a nonempty closed and convex subset of $H$, and let $A: C \rightarrow H$ be an L-Lipschitz continuous and monotone mapping. Assume that $V I(C, A)$ is not empty.

\begin{tabular}{|c|c|}
\hline EA: & Extragradient-type algorithm (for variational inequality (1.1)) \\
\hline $\begin{array}{l}\text { Step 0: } \\
\text { Step 1: }\end{array}$ & $\begin{array}{l}\text { Choose } x_{1} \in C, \lambda_{1} \in\left[\lambda, \lambda^{\prime}\right], \alpha_{1} \in[0,1) \text {. Set } n:=1 . \\
\text { Given } x_{n} \in C \text {. Choose } \lambda_{n} \in\left[\lambda, \lambda^{\prime}\right], \alpha_{n} \in[0,1) \text { and compute } x_{n+1} \in C \text { as } \\
\qquad \begin{array}{l}y_{n}=\operatorname{Proj}_{C}\left(x_{n}-\lambda_{n} A x_{n}\right), \\
\quad x_{n+1}=\alpha_{n} x_{n}+\left(1-\alpha_{n}\right) \operatorname{Proj}_{C}\left(x_{n}-\lambda_{n} A y_{n}\right) .\end{array} \\
=n+1 \text { and go to Step 1. }\end{array}$ \\
\hline
\end{tabular}

Table 1 The framework of the EA 
Table 2 The framework of the MA

\begin{tabular}{ll}
\hline MA: & Mann-type algorithm (for equilibrium problem (1.3)) \\
\hline Step 0: & Choose $x_{1} \in C, r_{1} \in(0,+\infty), \alpha_{1} \in[0,1)$. Set $n:=1$. \\
Step 1: & Given $x_{n} \in C$. Choose $r_{n} \in(0,+\infty), \alpha_{n} \in[0,1)$ and compute $x_{n+1} \in C$ as \\
& $\quad F\left(z_{n}, z\right)+\frac{1}{r_{n}}\left\langle z-z_{n}, z_{n}-x_{n}\right\rangle \geq 0$, \\
& $x_{n+1}=\alpha_{n} x_{n}+\left(1-\alpha_{n}\right) z_{n}$. \\
Update $n:=$ & $n+1$ and go to Step 1. \\
\hline
\end{tabular}

Let $\left\{\alpha_{n}\right\}$ be a real number sequence in $[0,1]$. Let $\left\{\lambda_{n}\right\}$ and $\left\{r_{n, m}\right\}$ be positive real number sequences. Let $\left\{x_{n}\right\}$ be a sequence generated in the following manner:

$$
\left\{\begin{array}{l}
x_{1} \in C \\
y_{n}=\operatorname{Proj}_{C}\left(x_{n}-\lambda_{n} A x_{n}\right), \\
x_{n+1}=\alpha_{n} x_{n}+\left(1-\alpha_{n}\right) \operatorname{Proj}_{C}\left(x_{n}-\lambda_{n} A y_{n}\right), \quad n \geq 1 .
\end{array}\right.
$$

Assume that $\left\{\alpha_{n}\right\}$ and $\left\{\lambda_{n}\right\}$ satisfy the following restrictions:

(a) $0 \leq \alpha_{n} \leq a^{\prime}<1$;

(b) $\lambda \leq \lambda_{n} \leq \lambda^{\prime}$, where $\lambda, \lambda^{\prime} \in(0,1 / L)$.

Then the sequence $\left\{x_{n}\right\}$ weakly converges to some point $\bar{x} \in V I(C, A)$.

Letting $F_{m}=F, B_{m}=B$ and $A=0$ in $\Gamma$, we have the Mann-type algorithm (see Table 2).

Corollary 2.5 Let $C$ be a nonempty closed and convex subset of $H$. Let $F$ be a bifunction from $C \times C$ to $\mathbb{R}$ which satisfies (A1)-(A4) such that $E P(F)$ is not empty. Let $\left\{\alpha_{n}\right\}$ be a real number sequence in $[0,1]$. Let $\left\{r_{n}\right\}$ be a positive real number sequence. Let $\left\{x_{n}\right\}$ be a sequence generated in the following manner:

$$
\left\{\begin{array}{l}
x_{1} \in C, \\
z_{n} \in C \text { such that } F\left(z_{n}, z\right)+\frac{1}{r_{n}}\left\langle z-z_{n}, z_{n}-x_{n}\right\rangle \geq 0, \\
x_{n+1}=\alpha_{n} x_{n}+\left(1-\alpha_{n}\right) z_{n}, \quad n \geq 1 .
\end{array}\right.
$$

Assume that $\left\{\alpha_{n}\right\}$ and $\left\{r_{n}\right\}$ satisfy the following restrictions:

(a) $0<a \leq \alpha_{n} \leq a^{\prime}<1$;

(b) $\liminf _{n \rightarrow \infty} r_{n}>0$.

Then the sequence $\left\{x_{n}\right\}$ weakly converges to some point $\bar{x} \in E P(F)$.

\section{Conclusion}

Generalized equilibrium problems have emerged as an effective and powerful tool for studying a wide class of problems which arise in economics, finance, image reconstruction, ecology, transportation, and network. The problems include variational inequality problems, saddle point problems, complementarity problems, Nash equilibrium problem in noncooperative games, and others as special cases. In this paper, we study monotone variational inequalities and generalized equilibrium problems based on a fixed point method. The extragradient algorithm is valid for a family of infinite bifunctions. We analyze the convergence of the algorithm and establish a weak convergence theorem for solutions under mild restrictions imposed on the control sequences. 


\section{Competing interests}

The author declares that he has no competing interests.

\section{Acknowledgements}

The author thanks the Fundamental Research Funds for the Central Universities (2014ZD44). The author is very grateful to the editor and anonymous reviewers for their suggestions which improved the contents of the article.

\section{Received: 3 September 2014 Accepted: 11 November 2014 Published: 01 Dec 2014}

\section{References}

1. Browder, FE, Petryshyn, WV: Construction of fixed points of nonlinear mappings in Hilbert space. J. Math. Anal. Appl. 20, 197-228 (1967)

2. liduka, $\mathrm{H}$, Takahashi, W: Strong convergence theorems for nonexpansive mappings and inverse-strongly monotone mappings. Nonlinear Anal. 61, 341-350 (2005)

3. Qin, X, Cho, SY, Wang, L: Iterative algorithms with errors for zero points of m-accretive operators. Fixed Point Theory Appl. 2013, Article ID 148 (2013)

4. Rockafellar, RT: On the maximality of sums of nonlinear monotone operators. Trans. Am. Math. Soc. 149, 75-88 (1970)

5. Wang, ZM, Lou, W: A new iterative algorithm of common solutions to quasi-variational inclusion and fixed point problems. J. Math. Comput. Sci. 3, 57-72 (2013)

6. Yang, S: Zero theorems of accretive operators in reflexive Banach spaces. J. Nonlinear Funct. Anal. 2013, Article ID 2 (2013)

7. Cho, SY, Kang, SM: Approximation of common solutions of variational inequalities via strict pseudocontractions. Acta Math. Sci. 32, 1607-1618 (2012)

8. Rockafellar, RT: Monotone operators and the proximal point algorithm. SIAM J. Control Optim. 14, 877-898 (1976)

9. Hao, Y: Zero Theorems of accretive operators. Bull. Malays. Math. Soc. 34, 103-112 (2011)

10. Cho, SY, Li, W, Kang, SM: Convergence analysis of an iterative algorithm for monotone operators. J. Inequal. Appl. 2013, Article ID 199 (2013)

11. Kim, JK, Buong, N: Regularization inertial proximal point algorithm for monotone hemicontinuous mapping and inverse strongly monotone mappings in Hilbert spaces. J. Inequal. Appl. 2010, Article ID 451916 (2010)

12. Wu, C, Sun, L: A monotone projection algorithm for fixed points of nonlinear operators. Fixed Point Theory Appl. 2013, Article ID 318 (2013)

13. Yuan, Q: Splitting methods for treating strictly pseudocontractive and monotone operators in Hilbert spaces. Adv. Fixed Point Theory 4, 263-279 (2014)

14. Qin, X, Cho, SY, Wang, L: Convergence of splitting algorithms for the sum of two accretive operators with applications. Fixed Point Theory Appl. 2014, Article ID 166 (2014)

15. Qin, X, Su, Y: Approximation of a zero point of accretive operator in Banach spaces. J. Math. Anal. Appl. 329, 415-424 (2007)

16. Blum, E, Oettli, W: From optimization and variational inequalities to equilibrium problems. Math. Stud. 63, 123-145 (1994)

17. Combettes, PL, Hirstoaga, SA: Equilibrium programming in Hilbert spaces. J. Nonlinear Convex Anal. 6, 117-136 (2005)

18. Hao, Y: Weak convergence theorems of a hybrid algorithm in Hilbert spaces. J. Inequal. Appl. 2014, Article ID 378 (2014)

19. Kim, JK: Strong convergence theorems by hybrid projection methods for equilibrium problems and fixed point problems of the asymptotically quasi- $\phi$-nonexpansive mappings. Fixed Point Theory Appl. 2011, Article ID 10 (2011)

20. Chen, JH: Iterations for equilibrium and fixed point problems. J. Nonlinear Funct. Anal. 2013, Article ID 4 (2013)

21. Zhang, L, Tong, H: An iterative method for nonexpansive semigroups, variational inclusions and generalized equilibrium problems. Adv. Fixed Point Theory 4, 325-343 (2014)

22. Cho, SY, Qin, X: On the strong convergence of an iterative process for asymptotically strict pseudocontractions and equilibrium problems. Appl. Math. Comput. 235, 430-438 (2014)

23. Zhang, M: Iterative algorithms for common elements in fixed point sets and zero point sets with applications. Fixed Point Theory Appl. 2012, Article ID 21 (2012)

24. Wang, ZM, Zhang, X: Shrinking projection methods for systems of mixed variational inequalities of Browder type, systems of mixed equilibrium problems and fixed point problems. J. Nonlinear Funct. Anal. 2014, Article ID 15 (2014)

25. Opial, Z: Weak convergence of the sequence of successive approximations for nonexpansive mappings. Bull. Am. Math. Soc. 73, 595-597 (1967)

26. Weng, XL: Fixed point iteration for local strictly pseudocontractive mappings. Proc. Am. Math. Soc. 113, 727-731 (1991)

27. Yang, L, Zhao, F, Kim, JK: Hybrid projection method for generalized mixed equilibrium problem and fixed point problem of infinite family of asymptotically quasi- $\phi$-nonexpansive mappings in Banach spaces. Appl. Math. Comput. $218,6072-6082(2012)$

10.1186/1687-1812-2014-236

Cite this article as: Wang: Monotone variational inequalities, generalized equilibrium problems and fixed point methods. Fixed Point Theory and Applications 2014, 2014:236 